\title{
Cycloosmathioborane Compounds: Other Manifestations of the Hückel Aromaticity
}

\author{
Miguel A. Esteruelas, ${ }^{*}{ }^{\dagger}$ Israel Fernández, ${ }^{\ddagger \odot}$ Cristina García-Yebra, ${ }^{\dagger}$ Jaime Martín, ${ }^{\dagger}$ \\ and Enrique Oñate ${ }^{\dagger}$
}

†Departamento de Química Inorgánica, Instituto de Síntesis Química y Catálisis Homogénea, Centro de Innovación en Química Avanzada (ORFEO-CINQA), Universidad de Zaragoza, CSIC, 50009 Zaragoza, Spain

${ }^{\star}$ Departamento de Química Orgánica I, Facultad de Ciencias Químicas, ORFEO-CINQA, Universidad Complutense de Madrid, 28040 Madrid, Spain

Supporting Information

ABSTRACT: The discovery of cycloosmathioborane compounds is reported. These species, which are prepared by the simultaneous dehydrogenation of a trihydride hydrogensulfide osmium(IV) complex and a $\mathrm{BH}_{3} \mathrm{NHR}_{2}$ amine-borane, bear an $\mathrm{Os}-\mathrm{S}-\mathrm{B}$ three-membered ring, being a manifestation of the $4 n+2$ Hückel aromaticity in which $n=0$ and where the two $\pi$ electrons of the ring are provided by the $\mathrm{S}$ atom.

A romaticity is a classic concept in chemistry that is continually evolving. ${ }^{1}$ It was initially introduced to account for the special properties of some unsaturated hydrocarbons and conjugated heterocycles. In 1979, Thorn and Hoffmann proposed its extension to organic aromatic compounds, where a $\mathrm{CH}$ unit was replaced by an isolobal transition-metal fragment, ${ }^{2}$ and 3 years later, Roper's group reported the first metallabenzene. ${ }^{3}$ Since then, a significant number of aromatic derivatives based on both carbon and transition elements have been isolated and characterized, ${ }^{4}$ most of them as Hückel aromatic species. $^{4 \mathrm{c}}$

Frogley and Wright recently defined metallaaromatic compounds as those bearing at least a transition metal in the ring, ${ }^{4 \mathrm{~d}}$ whereas in 1979, Bursten and Fenske used the term "metalloaromaticity" to describe the aromatic behavior that appeared to have been induced in cyclobutadiene as a result of its coordination to the $\mathrm{Fe}(\mathrm{CO})_{3}$ metal fragment. ${ }^{5}$ Nevertheless, metalloaromaticity has been employed by some authors without distinction for both situations. ${ }^{6}$ In addition, the term all-metal aromaticity has been invoked to address different aspects of the behavior of clusters of both main-group elements and transition metals. ${ }^{7}$

The cyclogallene dianion $\left[\mathrm{Ga}_{3} \mathrm{~L}_{3}\right]^{2-}\left(\mathrm{L}=\mathrm{Mes}_{2} \mathrm{C}_{6} \mathrm{H}_{3}\right)$ was the first compound of this class. ${ }^{8}$ Today, homoleptic aromatic 310-membered rings with elements of group 2 as well as of groups 13-16 are known, ${ }^{8}$ besides tripalladium ${ }^{10}$ and trigold cations. ${ }^{11}$ Three-membered ring compounds are certainly the most challenging because of the strain imposed by the small size of the ring. Computational methods have revealed that the aromaticity of group 14 cyclopropenylium analogues $\left(\mathrm{E}_{3} \mathrm{H}_{3}{ }^{+}\right)$ decreases in the sequence $\mathrm{C}>\mathrm{Si}>\mathrm{Ge}>\mathrm{Sn}>\mathrm{Pb}$. ${ }^{12}$ In addition to homoleptic species, a few heteroleptic species with two different main-group elements are also known. Cummins and co-workers have reported $\mathrm{EP}_{2}$ triangles $(\mathrm{E}=\mathrm{Ge}, \mathrm{Sn}, \mathrm{Pb})$, which are stabilized within the coordination sphere of a sterically protected diniobium unit, ${ }^{13}$ whereas Guha's group has computationally predicted that the substitution of a $\mathrm{B}$ atom in the triangle $\left[\mathrm{B}_{3} \mathrm{H}_{3}\right]^{2-}$ by a group 15 element should afford neutral aromatic $\mathrm{H}_{2} \mathrm{~B}_{2} \mathrm{XH}$ rings $(\mathrm{X}=\mathrm{N}, \mathrm{P}) .{ }^{14}$ Herein, we take one step forward in this fascinating field by reporting the preparation and full characterization of the first aromatic triangles having three different vertexes, namely, two main-group elements, $\mathrm{S}$ and B, and a transition metal with its associated ligands.

Scheme 1 summarizes the preparation of new compounds, which starts from the 9,9-dimethyl-4,5-bis-

Scheme 1. Synthetic Strategy for the Preparation of Cycloosmathioborane Complexes

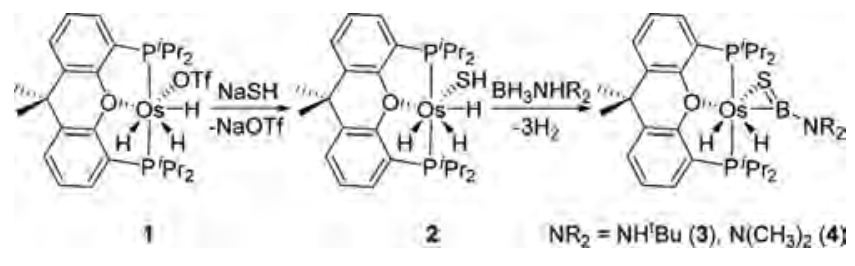

(diisopropylphosphine)xanthene complex $\mathrm{OsH}_{3}(\mathrm{OTf})\left\{\kappa^{3}\right.$ $\left.P, O, P-\left[\operatorname{xant}\left(\mathrm{P}^{i} \mathrm{Pr}_{2}\right)_{2}\right]\right\}(\mathbf{1})$ and takes place through the hydrogensulfide derivative $\mathrm{OsH}_{3}(\mathrm{SH})\left\{\kappa^{3}-\mathrm{P}, \mathrm{O}, \mathrm{P}-\left[\operatorname{xant}\left(\mathrm{P}^{i} \mathrm{Pr}_{2}\right)_{2}\right]\right\}$ (2; CCDC 1878692). Synthesis of the latter was inspired by the recent preparation of its hydroxo counterpart $\mathrm{OsH}_{3}(\mathrm{OH})\left\{\kappa^{3}\right.$ $\left.P, O, P-\left[\operatorname{xant}\left(\mathrm{P}^{i} \mathrm{Pr}_{2}\right)_{2}\right]\right\},{ }^{15}$ which is stable toward the reductive elimination of water despite this process is generally favored from a thermodynamic point of view. ${ }^{16}$ Similar to the $\mathrm{OH}^{-}$ group, $\mathrm{SH}^{-}$replaces the trifuoromethanesulfonate anion ([OTf $]^{-}$) from 1 to give 2 , which was isolated as red crystals in $47 \%$ yield. Coordination of the $\mathrm{SH}^{-}$group to the Os atom is demonstrated by the $\mathrm{X}$-ray diffraction analysis structure (Figure 1). The Os ${ }^{\mathrm{IV}}$ center shows the expected pentagonal-bipyramidal arrangement with axial $\mathrm{P}^{i} \mathrm{Pr}_{2}$ groups and the $\mathrm{O}$ atom of the diphosphine and the $\mathrm{SH}^{-}$anion in the perpendicular plane, along with the cisoid inequivalent hydrides, which display three resonances at $-8.07,-13.01$, and $-13.78 \mathrm{ppm}$ in the ${ }^{1} \mathrm{H}$ NMR

Received: December 3, 2018 


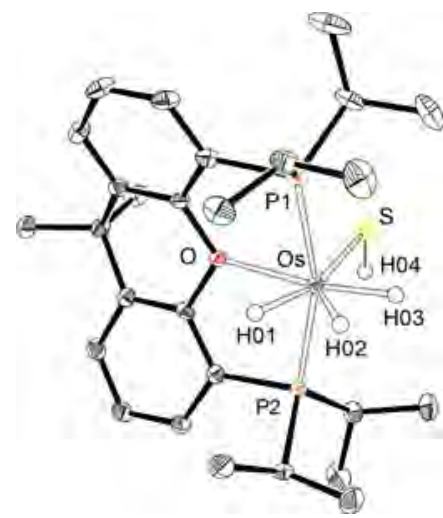

Figure 1. Molecular drawing of complex 2. $\mathrm{H}$ atoms (except hydrides and $\mathrm{H} 04$ ) are omitted for clarity.

spectrum in toluene- $d_{8}$ at $193 \mathrm{~K}$. The ${ }^{31} \mathrm{P}\left\{{ }^{1} \mathrm{H}\right\}$ NMR spectrum shows a singlet at $48.1 \mathrm{ppm}$ for the equivalent $\mathrm{P}^{i} \mathrm{Pr}_{2}$ groups. Complexes of platinum group metals bearing terminal hydrogensulfide ligands are rare because of the high tendency of this group to act as a bridging ligand. ${ }^{17}$ The five-coordinate catecholboryl derivative $\mathrm{Os}(\mathrm{Bcat})(\mathrm{SH})(\mathrm{CO})\left(\mathrm{P}^{i} \mathrm{Pr}_{3}\right)_{2}$ was the first mononuclear $\mathrm{SH}$ complex of these metals characterized by $\mathrm{X}$-ray diffraction analysis. It was prepared by reaction of the monohydride $\mathrm{OsH}(\mathrm{SH})(\mathrm{CO})\left(\mathrm{P}^{i} \mathrm{Pr}_{3}\right)_{2}{ }^{18}$ with $\mathrm{HBcat}$ via the dihydrogen intermediate $\mathrm{OsH}(\mathrm{SBcat})\left(\eta^{2}-\mathrm{H}_{2}\right)(\mathrm{CO})\left(\mathrm{P}^{i} \mathrm{Pr}_{3}\right)_{2}{ }^{19}$ Braun and co-workers have recently reported the rhodium(I) derivative $\mathrm{Rh}(\mathrm{SH})\left\{\kappa^{3}-P, O, P-\left[\operatorname{xant}\left({ }^{t} \mathrm{Bu}_{2}\right)_{2}\right]\right\}$, which has also been characterized by $\mathrm{X}$-ray diffraction analysis. ${ }^{20}$

Complex 2 reacts with $\mathrm{BH}_{3} \mathrm{NHR}_{2}$ amine-boranes to give the unprecedented cycloosmathioborane derivatives $\mathrm{OsH}_{2}\left\{\kappa^{2}-S, B\right.$ $\left[\mathrm{SBNR}_{2}\right]\left\{\kappa^{3}-\mathrm{P}, \mathrm{O}, \mathrm{P}-\left[\operatorname{xant}\left(\mathrm{P}^{i} \mathrm{Pr}_{2}\right)_{2}\right]\right\}\left[\mathrm{NR}_{2}=\mathrm{NH}^{t} \mathrm{Bu}(3 ; \mathrm{CCDC}\right.$ 1878693), $\mathrm{NMe}_{2}$ (4)], as a result of the release of $\mathrm{H}_{2}$ from both the metal center and amine-boranes. Dehydrogenation is favored by the polyhydride character of $2^{21}$ and by the presence of the hydrogensulfide ligand, which traps the resulting aminoborane monomer. $^{22}$ The capture facilitates the complete extraction of the $\mathrm{H}$ atoms attached to the $\mathrm{B}$ atom. Complexes 3 and 4 were isolated as yellow solids in about $60 \%$ yield. The Xray diffraction analysis structure of 3 (Figure 2) proves the triangular shape of the ring determined by the Os, S, and B atoms. The most noticeable feature of the triangle is the $\mathrm{B}-\mathrm{S}$ distance of $1.782(6) \AA$, which suggests a significant double-bond character. It is only about $0.03 \AA$ longer than the $\mathrm{B}-\mathrm{S}$ bond length reported in the manganese complex $\operatorname{Mn}\left(\eta^{5}-\mathrm{C}_{5} \mathrm{H}_{5}\right)\{\mathrm{S}=$ $\left.\mathrm{B}\left({ }^{t} \mathrm{Bu}\right) \mathrm{IMe}\right\}(\mathrm{CO})_{2} \quad[\mathrm{IMe}=1,3$-dimethylimidazolylidene;

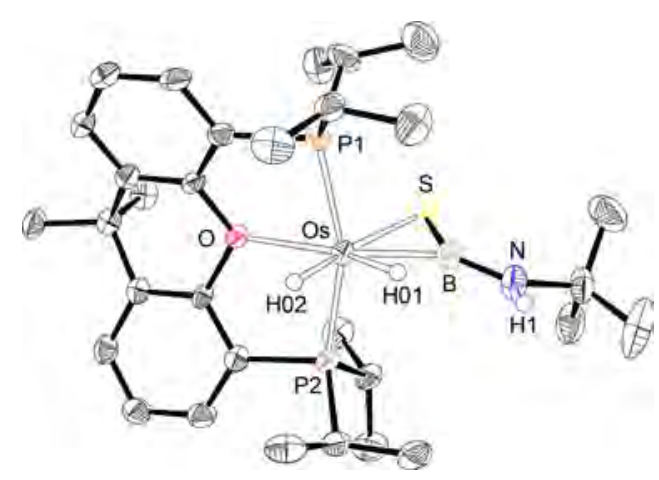

Figure 2. Molecular drawing of complex 3. $\mathrm{H}$ atoms (except hydrides and $\mathrm{H} 1$ ) are omitted for clarity.
$1.747(3) \AA]^{23}$ and in the thioxoboranes $\mathrm{S}=\mathrm{B}\left\{\kappa^{2}-N, N-[\mathrm{N}(2,6-\right.$ $\left.\left.\left.\mathrm{Me}_{2} \mathrm{C}_{6} \mathrm{H}_{3}\right) \mathrm{C}(\mathrm{Me}) \mathrm{CHC}(\mathrm{Me}) \mathrm{N}\left(2,6-\mathrm{Me}_{2} \mathrm{C}_{6} \mathrm{H}_{3}\right)\right]\right\} \quad[1.741(2)$ $\AA]^{24}$ and $\mathrm{S}=\mathrm{B}\left\{\kappa^{2}-\mathrm{N}, \mathrm{N}-\left[\mathrm{N}\left(2,4,6-\mathrm{Me}_{3} \mathrm{C}_{6} \mathrm{H}_{2}\right) \mathrm{P}(\mathrm{Ph})_{2} \mathrm{NP}(\mathrm{Ph})_{2} \mathrm{~N}-\right.\right.$ $\left.\left.\left(2,4,6-\mathrm{Me}_{3} \mathrm{C}_{6} \mathrm{H}_{2}\right)\right]\right\}[1.752(5) \AA]^{25}$ and about $0.07 \AA$ longer than that found in the cation $\mathrm{S}=\mathrm{B}\left\{\kappa^{2}-N, N-\left[\mathrm{N}\left(\mathrm{L}^{\mathrm{Mes}}\right)\right.\right.$ $\left.\left.\mathrm{CH}_{2} \mathrm{CH}_{2} \mathrm{~N}\left(\mathrm{~L}^{\mathrm{Mes}}\right)\right]\right\}^{+}\left[\mathrm{L}^{\mathrm{Mes}}=1,3\right.$-dimesitylimidazolinylidene; $1.710(5) \AA]$, ${ }^{26}$ species reported as the first ones featuring a $\mathrm{B}=\mathrm{S}$ double bond. The three-membered rings of 3 and 4 resemble that of the intermediate recently proposed by Braunschweig and co-workers for reaction of the alkylborylene complex $\mathrm{Mn}\left(\eta^{5}\right.$ $\left.\mathrm{C}_{5} \mathrm{H}_{5}\right)\left(=\mathrm{B}^{t} \mathrm{Bu}\right)(\mathrm{CO})_{2}$ with $\mathrm{SPPh}_{3}$, which yields the metathesis product $\mathrm{Mn}\left(\eta^{5}-\mathrm{C}_{5} \mathrm{H}_{5}\right)(\mathrm{CO})_{2}\left(\mathrm{PPh}_{3}\right)$. This intermediate has been suggested to be a $\kappa^{2}-S, B-\left[\mathrm{SB}^{t} \mathrm{Bu}\right]$ derivative. ${ }^{27}$ The $\mathrm{Os}-\mathrm{S}$ distance of $2.5572(14) \AA$ is scarcely $0.08 \AA$ longer than that of 2 , whereas the Os-B bond length of 2.073(6) $\AA$ is consistent with an $\mathrm{Os}^{\mathrm{IV}}-\mathrm{B}$ single bond. ${ }^{28}$ In fact, the $\mathrm{OsH}_{2}$ (POP) moiety can be described as a 16-electron valence cis-dihydride $\mathrm{L}_{5} \mathrm{Os}^{\mathrm{IV}}$ fragment, which gives rise to the typical pentagonal-bipyramidal arrangement around the metal center, with a mer coordination of the POP pincer. This arrangement generates two high-field signals at about -9 and $-18 \mathrm{ppm}$ in the ${ }^{1} \mathrm{H}$ NMR spectra and a singlet at about $47 \mathrm{ppm}$ in the ${ }^{31} \mathrm{P}\left\{{ }^{1} \mathrm{H}\right\}$ NMR spectra. Broad resonances at $56.3 \mathrm{ppm}$ for 3 and at $62.0 \mathrm{ppm}$ for 4 in the ${ }^{11} \mathrm{~B}$ NMR spectra are also characteristic features of these compounds.

Density functional theory (DFT) calculations at the dispersion-corrected BP86-D3/def2-TZVPP level were carried out on 3 to gain more insight into the bonding situation in the three-membered ring. Theoretical support for a significant double character of the $\mathrm{B}-\mathrm{S}$ bond is given by the corresponding computed Wiberg bond index of 1.40 and by the shapes of $\mathrm{HOMO}-7$ and HOMO-8 . They can be viewed as $\pi$ molecular orbitals delocalized within the ring, also involving the lone pair of the attached $\mathrm{N}$ atom (Figure 3 ). According of the natural
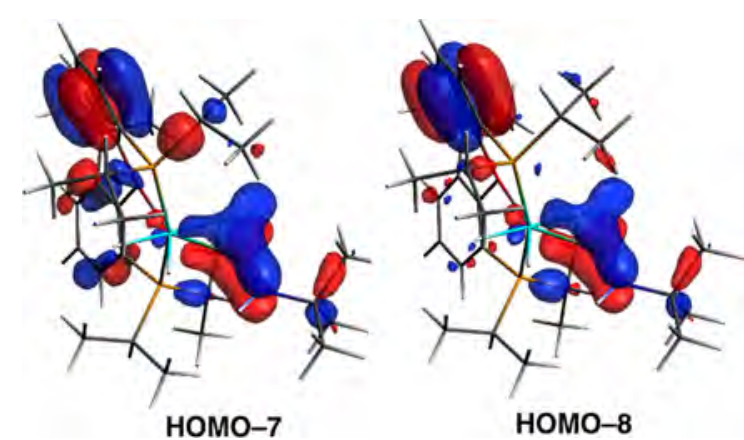

Figure 3. Computed $\pi$ molecular orbitals delocalized in the Os-B-S metallacycle of 3 (isosurface value of $0.04 \mathrm{au}$ ).

bond order (NBO) method, the multiple bond character of the $\mathrm{B}-\mathrm{S}$ bond derives from delocalization of the lone pair of the $\mathrm{S}$ atom into the vacant $\mathrm{p}_{z}$ atomic orbital of the $\mathrm{B}$ atom (associated second-order perturbation energy of $-55.7 \mathrm{kcal} / \mathrm{mol})$. In addition, the NBO method also locates a significant delocalization of a doubly occupied $\mathrm{d}_{\pi}(\mathrm{Os})$ atomic orbital to this vacant $\mathrm{p}_{z}$ (B) (associated energy of $-21.3 \mathrm{kcal} / \mathrm{mol}$ ), which is also fully consistent with the delocalized $\pi$ orbitals depicted in Figure 3.

The previously mentioned findings are consistent with a formally $4 n+2$ Hückel aromatic system in which $n=0$ and where the two $\pi$ electrons of the ring are provided by the $S$ atom. To confirm the aromaticity of the novel Os-S-B threemembered ring, we first computed the nuclear independent 
chemical shift (NICS) values at the center of the ring. A highly negative value of $\operatorname{NICS}(0)=-32.1 \mathrm{ppm}$ was found that would at first glance support the aromatic nature of the metallacycle. Nevertheless, it is well-known that isotropic NICS values, particularly in small rings, are usually contaminated by local shielding effects of the nearby bonds and therefore are not always reliable. ${ }^{12 a}$ The situation is even more dramatic if a transition metal is present in the ring. ${ }^{4 c}$ For this reason, we also computed the out-of-plane tensor contribution to the NICS value at $1 \AA$ above and below the ring center, which has been recommended as a reliable measure of the magnetic aromaticity. ${ }^{29}$ The highly negative computed values, NICS $(1)_{z z}$ $=-17.9$ and $-18.4 \mathrm{ppm}$, are overwhelming evidence of the aromatic nature of the $\mathrm{Os}-\mathrm{S}-\mathrm{B}$ metallacycle. In addition, the anisotropy of the induced current density (ACID) ${ }^{30}$ method was applied to visualize the aromatic ring current in the metallacycle. As depicted in Figure 4, the ACID method,

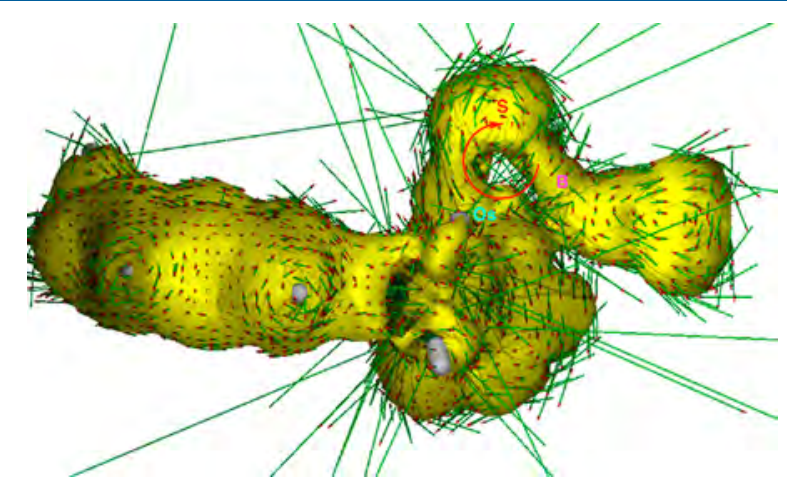

Figure 4. ACID plot for the model compound $\mathrm{OsH}_{2}\left\{\kappa^{2}-S, B\right.$ $\left[\mathrm{SBNH}_{2}\right]\left\{\kappa^{3}-\mathrm{P}, \mathrm{O}, \mathrm{P}-\left[\operatorname{xant}\left(\mathrm{PH}_{2}\right)_{2}\right]\right\}$ with a 0.04 au isosurface value.

computed for a model system where the bulky isopropyl and tert-butyl groups were replaced by $\mathrm{H}$ atoms $\left[\operatorname{NICS}(1)_{z z}=-15.9\right.$ ppm], clearly shows the occurrence of a diatropic (clockwise vectors) ring current within the three-membered ring, therefore confirming the aromatic nature of this novel metallacycle.

We have obtained additional support for the aromatic character of complexes 3 and $\mathbf{4}$ by means of energetic descriptors. However, the application of the energetic methods (ASE or ISE methods) ${ }^{4 c}$ typically used in other aromatic compounds, including those having transition metals in their structures, is not possible for these particular species. We have carried out two alternative isodesmic reactions, namely, the hydrogenation and reductive elimination depicted in Scheme 2. For both reactions, cleavage of the three-membered ring is computed to be endothermic, which is fully consistent with the thermodynamic stability (due to aromaticity) of the metallacycle.

In conclusion, the assembly of a 16-electron valence $\mathrm{L}_{5} \mathrm{Os}^{\mathrm{IV}}$ metal fragment, a $\mathrm{S}$ atom, and a B-NR $\mathrm{NR}_{2}$ moiety gives rise to threemembered $\pi$-aromatic rings, which are formed by different vertexes, representing a novel manifestation of the $4 n+2$ Hückel aromaticity in which $n=0$. These cycloosmathioborane compounds are prepared by the simultaneous dehydrogenation of a trihydride hydrogensulfide osmium(IV) complex and a $\mathrm{BH}_{3} \mathrm{NHR}_{2}$ amine-borane.
Scheme 2. Computed Isodesmic Reactions Involving Complex $3^{a}$

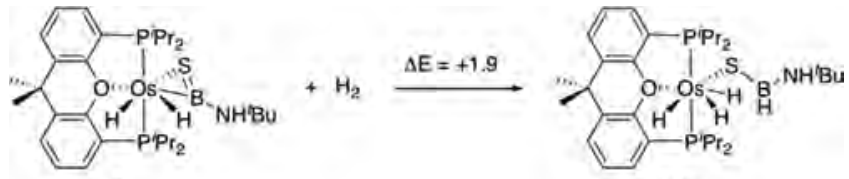

$3-\mathrm{H}_{2}$

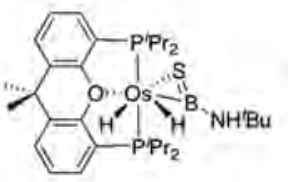

3

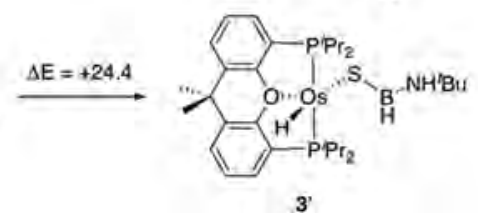

${ }^{a}$ Energies (in $\mathrm{kcal} / \mathrm{mol}$ ) were computed at the BP86-D3/def2TZVPP level.

\section{ASSOCIATED CONTENT}

\section{S Supporting Information}

The Supporting Information is available free of charge on the ACS Publications website at DOI: 10.1021/acs.inorgchem. 8 b03366.

General information, instrumental methods, preparation and characterization of 2-4, NMR spectra, structural analysis of $\mathbf{2}$ and 3, computational details, and ACID plot (PDF)

Cartesian coordinates (XYZ)

\section{Accession Codes}

CCDC 1878692-1878693 contain the supplementary crystallographic data for this paper. These data can be obtained free of charge via www.ccdc.cam.ac.uk/data_request/cif, or by emailing data_request@ccdc.cam.ac.uk, or by contacting The Cambridge Crystallographic Data Centre, 12 Union Road, Cambridge CB2 1EZ, UK; fax: +44 1223336033.

\section{AUTHOR INFORMATION}

\section{Corresponding Author}

*E-mail: maester@unizar.es.

\section{ORCID}

Miguel A. Esteruelas: 0000-0002-4829-7590

Israel Fernández: 0000-0002-0186-9774

Cristina García-Yebra: 0000-0002-5545-5112

Jaime Martín: 0000-0003-0909-3509

Enrique Oñate: 0000-0003-2094-719X

Notes

The authors declare no competing financial interest.

\section{ACKNOWLEDGMENTS}

We thank MINECO of Spain (Projects CTQ2017-82935-P, CTQ2016-78205-P, and Red de Excelencia Consolider CTQ2016-81797-REDC), DGA (No. E06_17R), FEDER, and the European Social Fund for financial support.

\section{DEDICATION}

Dedicated to Professor Pablo Espinet for his outstanding contribution to the field of organometallic compounds on the occasion of his 70th birthday. 


\section{REFERENCES}

(1) (a) Stanger, A. What is $\cdots$ Aromaticity: a Critique of the Concept of Aromaticity-Can it Really be Defined? Chem. Commun. 2009, 19391947. (b) Solà, M. Why Aromaticity Is a Suspicious Concept? Why? Front. Chem. 2017, 5, 22.

(2) Thorn, D. L.; Hoffmann, R. Delocalization in Metallocycles. Nouv. J. Chim. 1979, 3, 39-45.

(3) Elliott, G. P.; Roper, W. R.; Waters, J. M. Metallacyclohexatrienes or "Metallabenzenes". Synthesis of Osmabenzene Derivatives and XRay Crystal Structure of $\left[\mathrm{Os}(\mathrm{CSCHCHCHCH})(\mathrm{CO})\left(\mathrm{PPh}_{3}\right)_{2}\right] . J$. Chem. Soc., Chem. Commun. 1982, 811-813.

(4) (a) Bleeke, J. R. Metallabenzenes. Chem. Rev. 2001, 101, 12051227. (b) Cao, X.-Y.; Zhao, Q.; Lin, Z.; Xia, H. The Chemistry of Aromatic Osmacycles. Acc. Chem. Res. 2014, 47, 341-354. (c) Fernández, I.; Frenking, G.; Merino, G. Aromaticity of Metallabenzenes and Related Compounds. Chem. Soc. Rev. 2015, 44, 64526463. (d) Frogley, B. J.; Wright, L. J. Recent Advances in Metallaaromatic Chemistry. Chem. - Eur. J. 2018, 24, 2025-2038.

(e) Zhu, C.; Xia, H. Carbolong Chemistry: A Story of Carbon Chain Ligands and Transition Metals. Acc. Chem. Res. 2018, 51, 1691-1700.

(5) Bursten, B. E.; Fenske, R. F. Molecular Orbital Studies on Cyclobutadienemetal Complexes: The Concept of Metallooaromaticity. Inorg. Chem. 1979, 18, 1760-1765.

(6) (a) Masui, H. Metalloaromaticity. Coord. Chem. Rev. 2001, 219, 957-992. (b) Feixas, F.; Matito, E.; Poater, J.; Solà, M. Metalloaromaticity. WIREs Comput. Mol. Sci. 2013, 3, 105-122.

(7) (a) Boldyrev, A. I.; Wang, L. S. All-Metal Aromaticity and Antiaromaticity. Chem. Rev. 2005, 105, 3716-3757. (b) Tsipis, C. A. DFT Study of "All-Metal" Aromatic Compounds. Coord. Chem. Rev. 2005, 249, 2740-2762. (c) Zubarev, D. Y.; Averkiev, B. B.; Zhai, H.-J.; Wang, L.-S.; Boldyrev, A. I. Aromaticity and Antiaromaticity in Transition-Metal Systems. Phys. Chem. Chem. Phys. 2008, 10, 257-267. (d) Li, L.-J.; Ali, B.; Chen, Z.; Sun, Z.-M. Recent Advances in Aromatic Antimony Clusters. Chin. J. Chem. 2018, 36, 955-960.

(8) (a) Li, X.-W.; Pennington, W. T.; Robinson, G. H. A Metallic System with Aromatic Character. Synthesis and Molecular Structure of $\mathrm{Na}_{2}\left[\left(\mathrm{Mes}_{2} \mathrm{C}_{6} \mathrm{H}_{3}\right) \mathrm{Ga}\right]_{3}$ (Mes = 2,4,6- $\left.\mathrm{Me}_{3} \mathrm{C}_{6} \mathrm{H}_{2}\right)$ : The First Cyclogallane. J. Am. Chem. Soc. 1995, 117, 7578-7579. (b) Li, X. W.; Xie, Y. M.; Schreiner, P. R.; Gripper, K. D.; Crittendon, R. C.; Campana, C. F.; Schaefer, H. F.; Robinson, G. H. Cyclogallanes and Metalloaromaticity. Synthesis and Molecular Structure of Dipotassium Tris $((2,6-$ dimesityphenyl)cyclogallene), $\mathrm{K}_{2}\left[\left(\mathrm{Mes}_{2} \mathrm{C}_{6} \mathrm{H}_{3}\right) \mathrm{Ga}\right]_{3}$ (Mes = 2,4,6$\left.\mathrm{Mes}_{2} \mathrm{C}_{6} \mathrm{H}_{3}\right)$ : A Structural and Theoretical Examination. Organometallics 1996, 15, 3798-3803. (c) Robinson, G. H. Gallanes, Gallenes, Cyclogallenes, and Gallynes: Organometallic Chemistry about the Gallium-Gallium Bond. Acc. Chem. Res. 1999, 32, 773-782. (d) Wang, Y. Z.; Robinson, G. H. Organometallics of the Group 13 M-M Bond (M $=\mathrm{Al}, \mathrm{Ga}, \mathrm{In})$ and the Concept of Metalloaromaticity. Organometallics 2007, 26, 2-11.

(9) Maslowsky, E. Inorganic Metallocenes: The Structures and Aromaticity of Sandwich Compounds of the Transition Elements with Inorganic Rings. Coord. Chem. Rev. 2011, 255, 2746-2763.

(10) Blanchard, S.; Fensterbank, L.; Gontard, G.; Lacôte, E.; Maestri, G.; Malacria, M. Synthesis of Triangular Tripalladium Cations as Noble-Metal Analogues of the Cyclopropenyl Cation. Angew. Chem., Int. Ed. 2014, 53, 1987-1991.

(11) Robilotto, T. J.; Bacsa, J.; Gray, T. G.; Sadighi, J. P. Synthesis of a Trigold Monocation: An Isolobal Analogue of $\left[\mathrm{H}_{3}\right]^{+}$. Angew. Chem., Int. Ed. 2012, 51, 12077-12080.

(12) (a) Fernández, I.; Duvall, M.; I-Chia Wu, J.; Schleyer, P. v. R.; Frenking, G. Aromaticity in Group 14 Homologues of the Cyclopropenylium Cation. Chem. - Eur. J. 2011, 17, 2215-2224. (b) Fernández, I.; Wu, J. I.; Schleyer, P. v. R. Substituent Effects on "Hyperconjugative" Aromaticity and Antiaromaticity in Planar Cyclopolyenes. Org. Lett. 2013, 15, 2990-2993.

(13) Figueroa, J. S.; Cummins, C. C. Triatomic $\mathrm{EP}_{2}$ Triangles $(\mathrm{E}=\mathrm{Ge}$, $\mathrm{Sn}, \mathrm{Pb})$ as $\mu^{2}: \eta^{3}, \eta^{3}$-Bridging Ligands. Angew. Chem., Int. Ed. 2005, 44, $4592-4596$
(14) Ullah, S. S.; Mazumder, L. J.; Kaushik, S.; Das, N.; Brahma, M. S.; Sharma, P. K.; Guha, A. K. Electronic Structure, Stability, and Aromaticity of $\mathrm{H}_{2} \mathrm{~B}_{2} \mathrm{XH}(\mathrm{X}=\mathrm{N}, \mathrm{P})$ molecules: A Theoretical Study. Comput. Theor. Chem. 2017, 1113, 120-125.

(15) Esteruelas, M. A.; García-Yebra, C.; Martín, J.; Oñate, E. Dehydrogenation of Formic Acid Promoted by a Trihydride-HydroxoOsmium(IV) Complex: Kinetics and Mechanism. ACS Catal. 2018, 8, 11314-11323.

(16) Ozerov, O. V. Oxidative Addition of Water to Transition Metal Complexes. Chem. Soc. Rev. 2009, 38, 83-88.

(17) For osmium complexes bearing bridging SH groups, see: (a) Au, Y.-K.; Cheung, K.-K.; Wong, W.-T. Synthesis and Structural Characterization of Ruthenium and Osmium Carbonyl Clusters Containing 4,6Dimethylpyrimidine-2-thione. Inorg. Chim. Acta 1995, 228, 267-275. (b) Au, Y.-K.; Cheung, K.-K.; Wong, W.-T. Synthesis, Structural Characterization and Thermal Reactivities of Osmium Carbonyl Clusters Containing 4,6-Dimethylpyrimidine-2-thione. J. Chem. Soc., Dalton Trans. 1995, 1047-1057. (c) Reyes-López, O. R.; Leyva, M. A.; Rosales-Hoz, M. J. Structural Characterization of $\left[(\mu-\mathrm{H}) \mathrm{Os}_{3}(\mathrm{CO})_{10}(\mu\right.$ $\left.\left.\mathrm{NH}_{2}\right)\right]$ and a New Polymorphic form of $\left[(\mu-\mathrm{H}) \mathrm{Os}_{3}(\mathrm{CO})_{10}(\mu-\mathrm{SH})\right]$. Influence of the Bridging Group on the Geometry of Compounds $[(\mu$ $\left.\mathrm{H}) \mathrm{Os}_{3}(\mathrm{CO})_{10}(\mu-\mathrm{X})\right]\left(\mathrm{X}=\mathrm{NH}_{2}, \mathrm{NRH}, \mathrm{PRH}, \mathrm{SbR}_{2}, \mathrm{OH}, \mathrm{SH}, \mathrm{SR}, \mathrm{SeR}\right.$, $\mathrm{Cl}, \mathrm{Br})$. Reactions of $\left[(\mu-\mathrm{H}) \mathrm{Os}_{3}(\mathrm{CO})_{10}(\mu-\mathrm{X})\right](\mathrm{X}=\mathrm{OH}$ and $\mathrm{SH})$ with Proton Sponge. J. Mol. Struct. 2011, 985, 134-138.

(18) Buil, M. L.; Elipe, S.; Esteruelas, M. A.; Oñate, E.; Peinado, E.; Ruiz, N. Five-Coordinate Complexes $\mathrm{MHCl}(\mathrm{CO})\left(\mathrm{P}^{i} \operatorname{Pr}_{3}\right)_{2}(\mathrm{M}=\mathrm{Os}$, $\mathrm{Ru})$ as Precursors for the Preparation of New Hydrido- and AlkenylMetallothiol and Monothio- $\beta$-Diketonato Derivatives. Organometallics 1997, 16, 5748-5755.

(19) Esteruelas, M. A.; López, A. M.; Mora, M.; Oñate, E. B-H Activation and $\mathrm{H}-\mathrm{H}$ Formation: Two Consecutive Heterolytic Processes on an Osmium-Hydrogensulfide Bond. Chem. Commun. 2013, 49, 7543-7545.

(20) Wozniak, M.; Braun, T.; Ahrens, M.; Braun-Cula, B.; Wittwer, P.; Herrmann, R.; Laubenstein, R. Activation of $\mathrm{SF}_{6}$ at a Xantphos-Type Rhodium Complex. Organometallics 2018, 37, 821-828.

(21) (a) Esteruelas, M. A.; López, A. M.; Mora, M.; Oñate, E. Ammonia-Borane Dehydrogenation Promoted by an Osmium Dihydride Complex: Kinetics and Mechanism. ACS Catal. 2015, 5, 187-191. (b) Esteruelas, M. A.; López, A. M.; Oliván, M. Polyhydrides of Platinum Group Metals: Nonclassical Interactions and $\sigma$-Bond Activation Reactions. Chem. Rev. 2016, 116, 8770-8847.

(22) Esteruelas, M. A.; Fernández, I.; López, A. M.; Mora, M.; Oñate, E. Osmium-Promoted Dehydrogenation of Amine-Boranes and B-H Bond Activation of the Resulting Amino-Boranes. Organometallics 2014, 33, 1104-1107.

(23) Liu, S. Y.; Légaré, M.-A.; Auerhammer, D.; Hofmann, A.; Braunschweig, H. The First Boron-Tellurium Double Bond: Direct Insertion of Heavy Chalcogens into a $\mathrm{Mn}=\mathrm{B}$ Double Bond. Angew. Chem., Int. Ed. 2017, 56, 15760-15763.

(24) Wang, H.; Zhang, J. Y.; Hu, H. F.; Cui, C. M. Access to B = S and $\mathrm{B}=$ Se Double Bonds via Sulfur and Selenium Insertion into a B-H Bond and Hydrogen Migration. J. Am. Chem. Soc. 2010, 132, 1099810999.

(25) Jaiswal, K.; Prashanth, B.; Ravi, S.; Shamasundar, K. R.; Singh, S. Reactivity of a Dihydroboron Species: Synthesis of a Hydroborenium Complex and an Expedient Entry into Stable Thioxo- and SelenoxoBoranes. Dalton Trans 2015, 44, 15779-15785.

(26) Franz, D.; Irran, E.; Inoue, S. Isolation of a Three-Coordinate Boron Cation with a Boron-Sulfur Double Bond. Angew. Chem., Int. Ed. 2014, 53, 14264-14268.

(27) Bauer, J.; Braunschweig, H.; Damme, A.; Carlos, J. O.; Kramer, J.H. T.; Radacki, K.; Shang, R.; Siedler, E.; Ye, Q. Metathesis Reactions of a Manganese Borylene Complex with Polar Heteroatom-Carbon Double Bonds: A Pathway to Previously Inaccessible Carbene Complexes. J. Am. Chem. Soc. 2013, 135, 8726-8734.

(28) (a) Esteruelas, M. A.; Fernández, I.; López, A. M.; Mora, M.; Oñate, E. Preparation, Structure, Bonding, and Preliminary Reactivity of a Six-Coordinate $\mathrm{d}^{4}$ Osmium-Boryl Complex. Organometallics 2012, 
31, 4646-4649. (b) Buil, M. L.; Esteruelas, M. A.; Fernández, I.; Izquierdo, S.; Oñate, E. Cationic Dihydride Boryl and Dihydride Silyl Osmium(IV) NHC Complexes: A Marked Diagonal Relationship. Organometallics 2013, 32, 2744-2752.

(29) Fallah-Bagher-Shaidaei, H.; Wannere, C. S.; Corminboeuf, C.; Puchta, R.; Schleyer, P. v. R. Which NICS Aromaticity Index for Planar $\pi$ Rings is Best? Org. Lett. 2006, 8, 863-866.

(30) (a) Herges, R.; Geuenich, D. Delocalization of Electrons in Molecules. J. Phys. Chem. A 2001, 105, 3214-3220. (b) Geuenich, D.; Hess, K.; Köhler, F.; Herges, R. Anisotropy of the Induced Current Density (ACID), a General Method to Quantify and Visualize Electronic Delocalization. Chem. Rev. 2005, 105, 3758-3772. 